\title{
Perawatan Ortodontik menggunakan Teknik Begg pada Kasus Pencabutan Satu Gigi Insisivus Inferior dan Frenectomy Labialis Superior
}

\author{
Shella Indri Novianty, Wayan Ardhana, dan Christnawati
}

Program Studi Ortodonsia, PPDGS, Fakultas Kedokteran Gigi, Universitas Gadjah Mada JI Denta No 1 Sekip Utara, Yogyakarta, Indonesia; e-mail: shella_lapiz@yahoo.com

\begin{abstract}
ABSTRAK
Pencabutan gigi insisivus rahang bawah merupakan salah satu cara yang digunakan untuk mendapatkan ruang pada perawatan ortodontik. Seleksi kasus yang ketat harus dilakukan sebelum menentukan pencabutan gigi tersebut, agar mendapatkan hasil perawatan yang baik. Artikel ini memaparkan hasil perawatan menggunakan alat cekat teknik Begg pada kasus maloklusi Angle klas I disertai dengan spacing anterior rahang atas dan pencabutan satu gigi insisivus sentralis rahang bawah, serta frenektomi frenulum labialis superior pada seorang wanita berumur 47 tahun yang datang dengan diagnosa kasus maloklusi Angle klas I, skeletal klas I disertai protrusif bimaksiler, bidental protrusif, spacing anterior rahang atas, crowding anterior rahang bawah dan beberapa malposisi gigi individual pada kedua rahang. Frenektomi pada frenulum labialis superior dan pencabutan insisivus sentralis kiri rahang bawah dilakukan untuk mencapai tujuan perawatan. Perawatan aktif dimulai pada bulan September 2012 menggunakan alat cekat teknik Begg dan berakhir pada bulan September 2013. Retraksi anterior dilakukan pada rahang atas sebesar 5,0 mm dan rahang bawah sebesar $2,5 \mathrm{~mm}$. Observasi pada hasil akhir perawatan terlihat ada perubahan yang baik pada profil, susunan gigi geligi dan analisis sefalometri. Pada pemeriksaan studi model diperoleh hasil bahwa overjet akhir 3,5 mm, overbite 3,0 mm, interdigitasi baik, dan median line rahang atas dan rahang bawah tidak segaris. Pencabutan satu gigi insisivus sentralis rahang bawah pada kasus maloklusi Angle klas I dengan spacing anterior rahang atas dan dilakukan perawatan dengan alat cekat teknik Begg, memberikan hasil perawatan yang cukup memuaskan.
\end{abstract}

Maj Ked Gi. Desember 2014; 21(2): 197 - 203

Kata Kunci: Maloklusi Angle Klas I, spacing anterior, pencabutan insisivus mandibula, alat cekat teknik Begg

ABSTRACT: Orthodontic Treatment Using Begg Technique In The Case of Extraction of One Inferior Incisor Tooth and Superior Labial Frenectomy. Extraction of lower arch incisive was the alternative way for space gaining on orthodontic treatment. Case selection is needed before deciding the extraction in order to achieve optimal orthodontic treatment result. The Objectives of this study is to report the result of orthodontic treatment using Begg technique appliance on Angle's class I malocclusion with spacing anterior at the upper arch, extraction of one incisive central at the lower arch and frenectomy of frenulum labial superior. A 47 years old woman was diagnosed as Angle's class I malocclusion, class I skeletal with bimaxillary protrusion, bidental protrusion, spacing anterior on the upper arch, crowding anterior on the lower arch, and tooth malposition on both arches. Frenectomy at frenulum labii superior and extraction of one incisive central at the lower arch were done for the orthodontic treatment. Orthodontic treatment was started on September 2012 and finished on September 2013. The upper anterior were $5 \mathrm{~mm}$ retracted and the lower anterior were $2.5 \mathrm{~mm}$ retracted. An observation at the end of treatment showed improvement in profile, alignment of the teeth, and skeletal appraisal. Study model observation showed $3.5 \mathrm{~mm}$ of overjet, $3.0 \mathrm{~mm}$ of overbite, good interdigitation, and median line shifting of the lower arch anterior. Extraction of one incisive central at the lower arch, for Orthodontic treatment on Angle's class I malocclusion with spacing anterior at the upper arch using Begg technique appliance showed an excellent result. Maj Ked Gi. Desember 2014; 21(2): 197 - 203

Keywords: Angle's class I Malocclusion, spacing anterior, incisive mandible extraction, Begg technique appliance

\section{PENDAHULUAN}

Ruangan yang mencukupi sangat dibutuhkan dalam perawatan ortodontik untuk menggerakkan gigi ke posisi yang ideal. Ruangan tersebut bermanfaat untuk retraksi gigi-gigi anterior, perbaikan curve of spee, dan koreksi gigi-gigi berjejal. Terdapat beberapa metode untuk memperoleh ruang pada perawatan ortodontik, yaitu proximal stripping, ekspansi, distalisasi gigi geligi, uprighting gigi molar, proklinasi gigi anterior, dan pencabutan. ${ }^{1}$ Salah satu keputusan pencarian ruang yang kerap menjadi kontroversi adalah pencabutan gigi. Pertimbangan pencabutan gigi sebagai cara untuk pencarian ruang dalam perawatan ortodontik mulai 


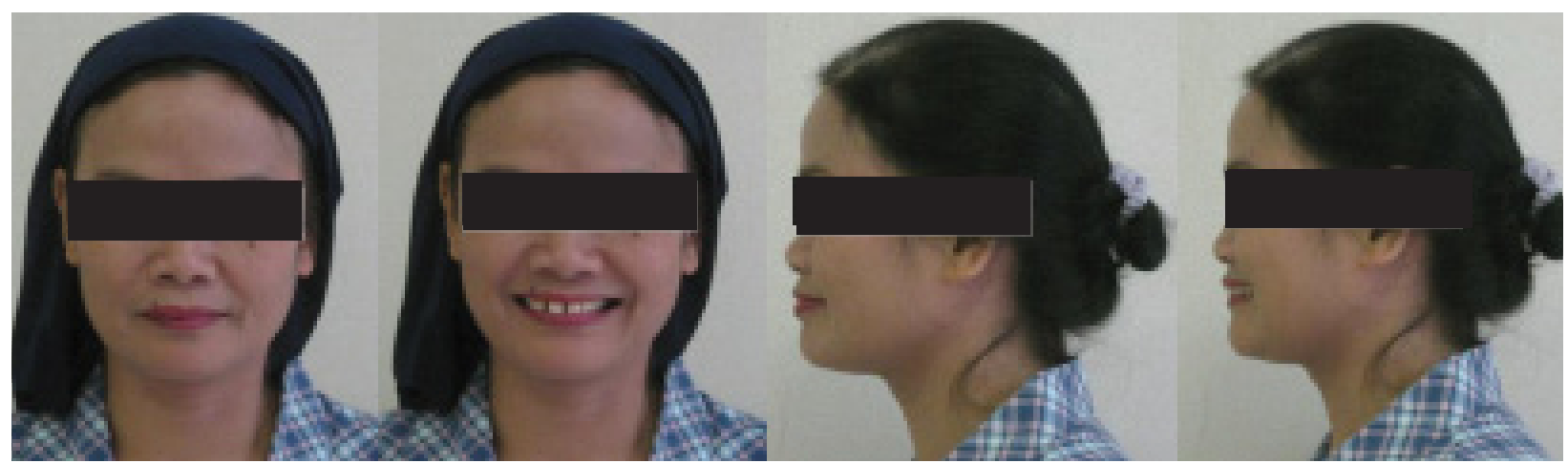

Gambar 1. Profil wajah pasien sebelum perawatan

berkembang pada pertengahan tahun 1900an. ${ }^{2}$ Pada awal tahun 1960an lebih dari setengah Ortodontis telah melakukan pencabutan gigi untuk pencarian ruang. Premolar pertama adalah gigi yang paling sering dicabut untuk tujuan tersebut. ${ }^{1}$

Pencabutan gigi insisivus rahang bawah merupakan salah satu langkah yang dapat ditempuh untuk pencarian ruang dalam perawatan ortodontik. Pencabutan gigi insisivus rahang bawah bukan merupakan keputusan yang populer untuk dilakukan, akan tetapi bukan berarti tidak boleh dilakukan. Keputusan tersebut tentu saja harus didasarkan pada keadaan gigi geligi pasien dan kebutuhan perawatan. ${ }^{3}$ Diagnostic setup sangat dibutuhkan dalam pengambilan keputusan pencabutan gigi insisivus bawah. Metode perhitungan untuk menentukan diskrepansi lengkung gigi dinilai kurang akurat untuk menunjukkan prediksi hasil perawatan. Diagnostic setup memiliki kemampuan untuk menunjukkan prediksi hasil perawatan lebih akurat, sebagai contoh untuk mengetahui interdigitasi yang baik. ${ }^{2}$

Perencanaan perawatan ortodontik yang tidak hati-hati pada pencabutan gigi insisvus rahang bawah akan menyebabkan hasil akhir perawatan tidak memuaskan. Melalui pemilihan kasus dan perencanaan perawatan yang ketat, pencabutan gigi insisivus rahang bawah akan memberikan keuntungan bagi Ortodontis yaitu berupa perawatan yang lebih sederhana dengan hasil yang memuaskan. ${ }^{4}$ Gigi insisivus rahang bawah dengan derajat malposisi yang paling parah adalah yang dianjurkan untuk dicabut. Hal tersebut dilakukan untuk menghindari gerakan yang berlebihan dan tidak dibutuhkan pada gigi geligi sehingga mencegah relaps pasca perawatan. ${ }^{5}$

Indikasi pencabutan gigi insisivus rahang bawah dalam perawatan ortodontik diantaranya adalah gigi geligi permanen, potensi pertumbuhan minimal, oklusi molar klas I Angle, profil jaringan lunak masih cukup harmonis, pada rahang atas tidak terdapat atau sedikit terdapat gigi berjejal, interdigitasi posterior baik, dan diskrepansi minimal lengkung gigi adalah $5 \mathrm{~mm} .{ }^{4,6}$ Indikasi lainnya adalah maloklusi klas III dengan derajat ringan sampai berat, oklusi edge-to-edge atau cross bite anterior, overbite minmal atau terdapat kecenderungan open bite, supernumerary insisivus rahang bawah, insisivus rahang bawah yang ektopik, dan gigi insisivus dengan tambalan yang sudah tidak baik ataupun yang mengalami masalah periodontal pada derajat parah. ${ }^{8}$ Pada kasus dengan overjet dan overbite positif yang besar, pencabutan gigi insisivus rahang bawah merupakan kontraindikasi karena akan menambah besarnya overjet dan overbite pada saat penutupan ruang di bagian anterior. ${ }^{3,7}$

Tujuan studi kasus ini adalah untuk memaparkan keberhasilan perawatan dengan teknik begg pada kasus dengan pencabutan satu gigi insisivus inferior dan frenektomi labialis superior dengan waktu perawatan yg relatif pendek. Pasien telah menyatakan persetujuan untuk dipublikasikan dalam laporan kasus ini demi kepentingan ilmu pengetahuan. 


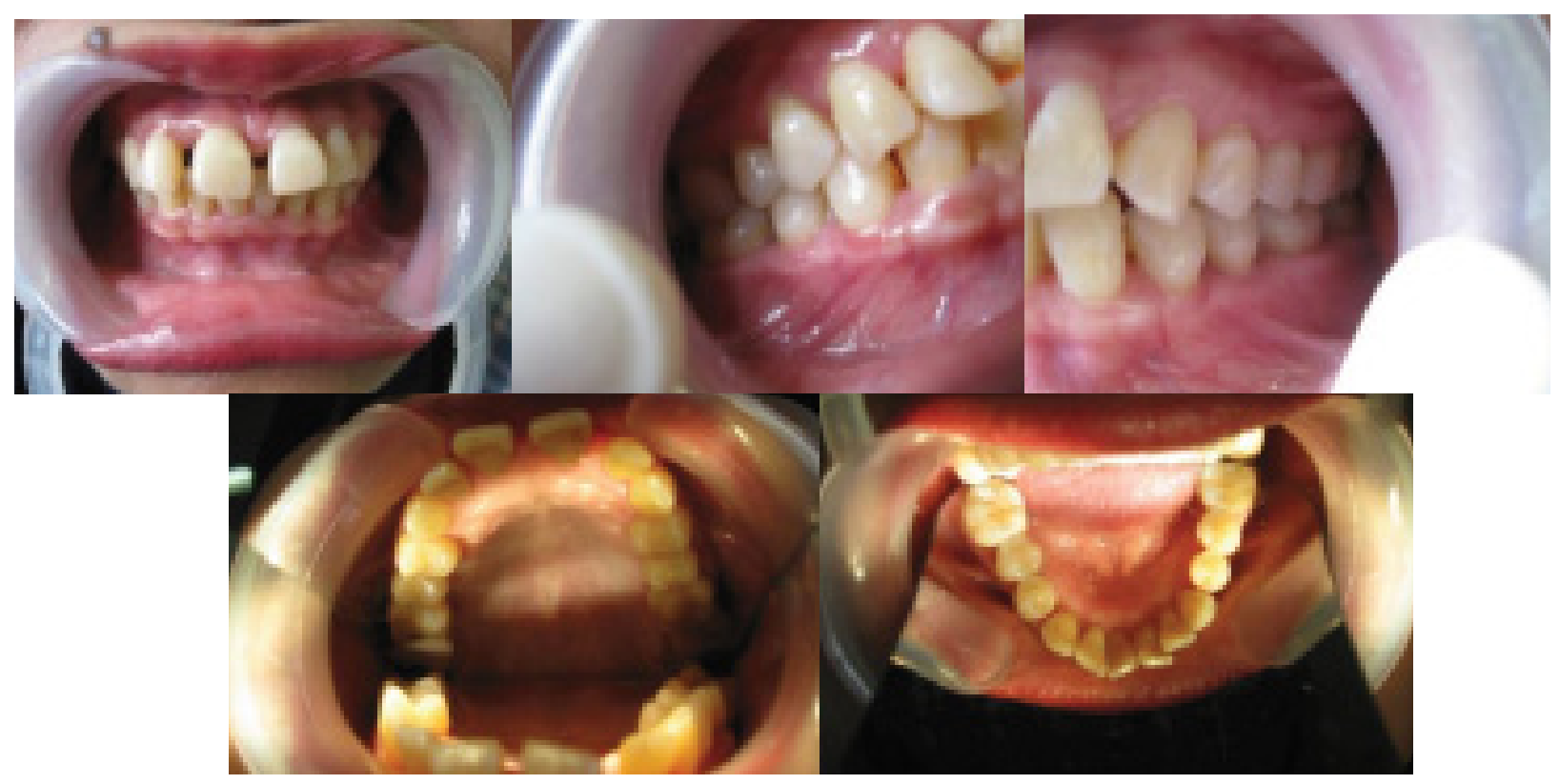

Gambar 2. Kondisi gigi geligi sebelum perawatan

\section{METODE}

Pasien wanita, 47 tahun, pada tanggal 4 Juni 2012 datang ke klinik spesialis Ortodonsi, RSGM FKG UGM, Yogyakarta. Pasien ingin merapikan gigi-gigi depan rahang atas yang terlihat maju dan renggang sehingga menyebabkan penurunan rasa percaya diri. Berdasarkan anamnesis diketahui bahwa kondisi gigi geligi pasien mirip dengan ayah dan ibu pasien. Ayah pasien memiliki gigi geligi maju dan ibu memiliki gigi depan yang renggang. Pasien memiliki profil cembung dan bentuk muka mesoprosop simetris (gambar 1).

Berdasarkan pemeriksaan objektif diketahui bahwa overbite $3.5 \mathrm{~mm}$, overjet $5.0 \mathrm{~mm}$, relasi molar adalah klas I Angle, median line rahang atas dan rahang bawah segaris, ukuran mesiodistal gigi 16, 13, dan 26 lebih kecil dari normal, interdigitasi posterior baik, spacing anterior rahang atas, gigi berjejal pada anterior rahang bawah dan terdapat beberapa malposisi gigi individual, serta frenulum labii superior pasien tinggi (gambar 2). Blanche test dilakukan untuk mengetahui apakah spacing pada insisivus sentralis rahang atas disebabkan oleh adanya jaringan lunak dari frenulum labii superior yang meluas sampai daerah palatal. Hasil dari tes ini adalah bahwa frenulum labii superior yang terlalu tinggi merupakan penyebab spacing anterior.
Setelah dilakukan analisis model studi dengan metode Pont, Korkhous, Howes, dan analisis sefalometri menggunakan analisis Down, Steiner, dan Wits maka diagnosis pada kasus ini adalah maloklusi Ange klas I, dengan skeletal klas I, protrusif bimaksiler, bidental protrusif, spacing anterior rahang atas, crowding anterior rahang bawah, dan beberapa malposisi gigi individual, serta disertai dengan frenulum labii superior tinggi.

Berdasarkan hasil determinasi lengkung gigi diketahui diskrepansi lengkung gigi pada rahang atas adalah $0 \mathrm{~mm}$ dan pada rahang bawah sebesar $-4.2 \mathrm{~mm}$ (-1.4 mm pada sisi kanan dan -2.8 mm pada sisi kiri). Pada anterior rahang atas akan dilakukan retraksi sebesar $5.0 \mathrm{~mm}$ dan rahang bawah $2.5 \mathrm{~mm}$ sehingga akan diperoleh overjet akhir sebesar $3.5 \mathrm{~mm}$. Retraksi $5.0 \mathrm{~mm}$ pada rahang atas selain untuk koreksi inklinasi dan profil, juga bertujuan untuk koreksi spacing anterior rahang atas. Pada rahang bawah diputuskan untuk melakukan pencabutan gigi 31. Gigi 31 mengalami malposisi berupa mesiolabiotorsiversi dan dengan pencabutan gigi tersebut akan menghasilkan ruang sebesar $4.2 \mathrm{~mm}$. Prediksi hasil akhir perawatan diaplikasikan pada diagnostic setup, seperti pada gambar 3. 


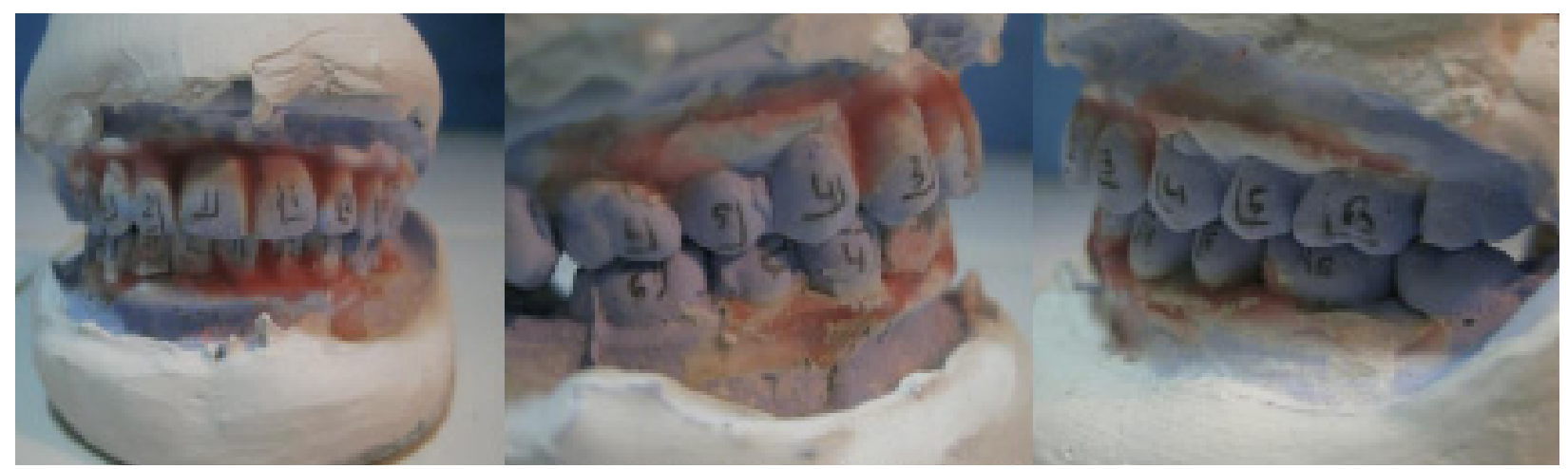

Gambar 3. Diagnostic setup pasien

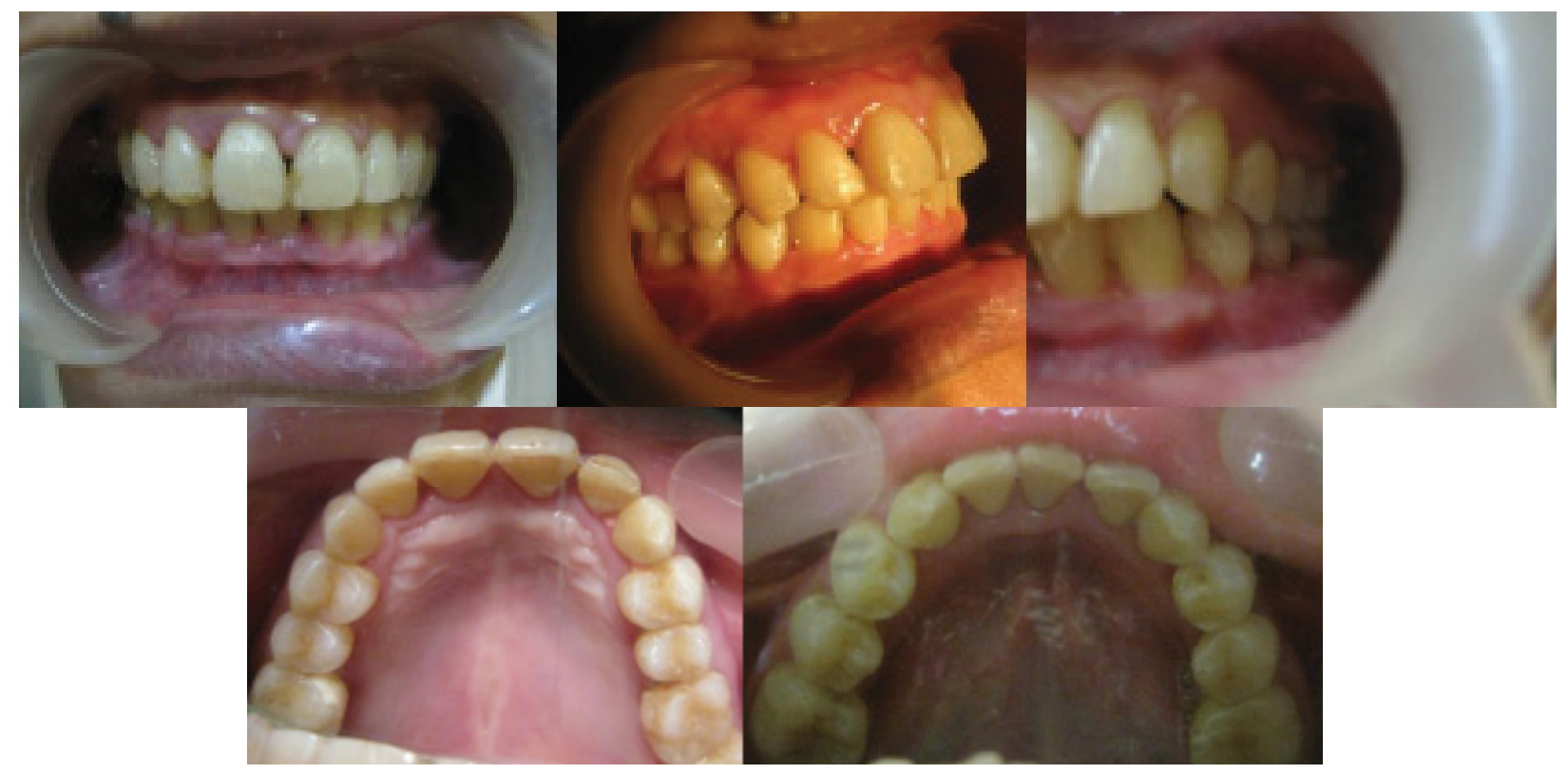

Gambar 4. Kondisi gigi geligi pasien sesudah perawatan

Sebelum perawatan ortodontik dimulai, dilakukan frenektomi pada frenulum labialis superior yang terlalu tinggi dan pencabutan gigi 31 . Perawatan ortodontik dilakukan dengan alat cekat teknik Begg slot 0,022" dan dimulai pada bulan September 2012. Band dengan round buccal tube di pasang pada gigi $16,26,36$, dan 46 . Perawatan ortodontik dengan menggunakan teknik Begg terdiri dari 3 tahap. Pada kasus ini, tahap I bertujuan untuk levelling dan unravelling, bite opening, dan retraksi anterior rahang bawah agar tercapai kondisi relasi interinsisal edge to edge. Untuk mencapai tujuan tersebut, maka pada rahang atas dan bawah digunakan busur kawat (australian wire) 0,014 " yang dilengkapi dengan anchorage bend $45^{\circ}$ di interdental gigi P2 dan M1, vertical loop pada regio anterior dengan jarak antar loop disesuaikan dengan lebar mesiodistal gigi-gigi anterior, circle loop di mesial braket $C$, elastik intermakasiler klas II 5/16" 2 oz, dan bypass pada semua gigi P2.

Tahap 2 yang bertujuan untuk space closing tidak dilakukan pada kasus ini. Hal ini disebabkan oleh tidak ada ruang yang tersisa pada saat akhir tahap 1. Tahap 3 dilakukan utnuk koreksi inklinasi gigi-gigi rahang atas dan rahang bawah dengan menggunakan busur kawat (Australian wire) 0,020" yang dilengkapi dengan anchorage bend $15^{\circ} \mathrm{di}$ interdental P2 dan M1, circle loop di mesial braket C, elastic intermaksiler klas II 5/16" 2 Oz, uprighting 


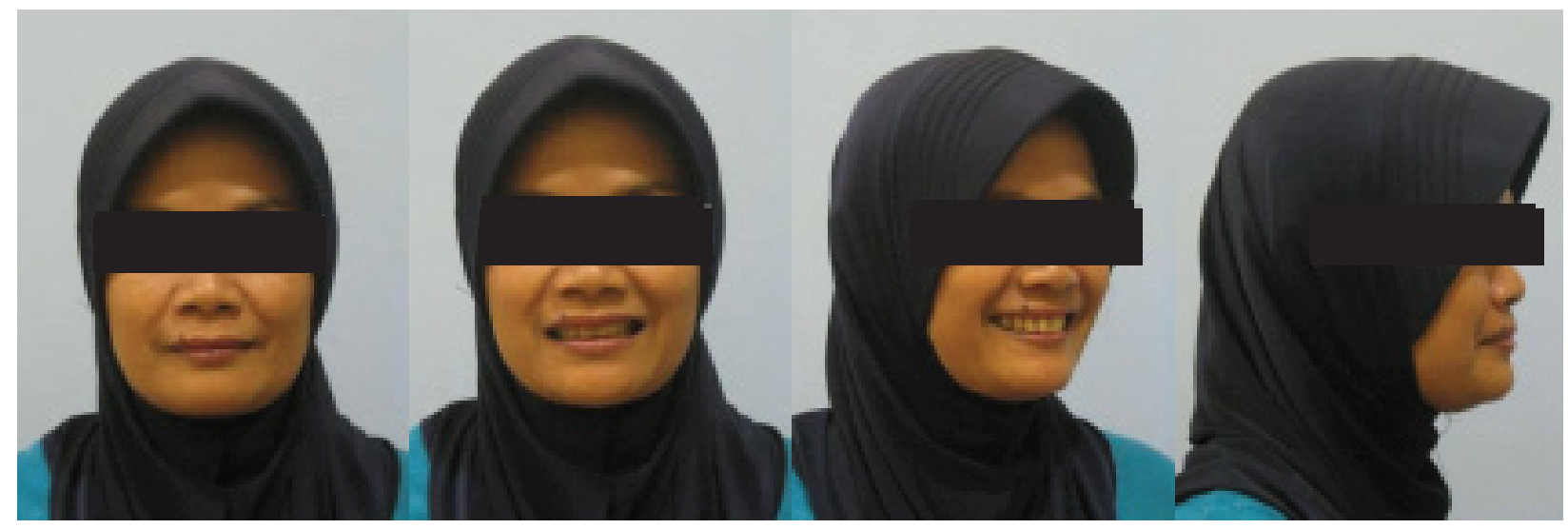

Gambar 5. Profil pasien sesudah perawatan

Tabel 1. Perhitungan sefalometri sebelum dan sesudah perawatan

\begin{tabular}{|c|c|c|c|}
\hline Ukuran & Nilai normal & Sebelum Perawatan & Akhir Perawatan \\
\hline Facial Angle & $82^{0}-92^{0}$ & $93^{0}$ & $90^{\circ}$ \\
\hline Angle of convexity & $-8,5^{0}-10^{0}$ & $-15^{0}$ & $+5^{0}$ \\
\hline Bidang A-B & $-9^{0}-0^{0}$ & $+8^{0}$ & $-4^{0}$ \\
\hline FMPA & $17^{0}-28^{0}$ & $26^{0}$ & $19^{\circ}$ \\
\hline Y Axis & $53^{0}-66^{0}$ & $62^{0}$ & $57,5^{0}$ \\
\hline SNA & $82^{0}$ & $80^{\circ}$ & $82^{0}$ \\
\hline SNB & $80^{\circ}$ & $88^{\circ}$ & $80^{\circ}$ \\
\hline ANB & $2^{0}$ & $-8^{0}$ & $2^{0}$ \\
\hline GoGn-SN & $32^{0}$ & $29^{\circ}$ & $25^{0}$ \\
\hline U1-L1 & $120^{\circ}-150^{\circ}$ & $120^{\circ}$ & $131^{\circ}$ \\
\hline U1-NA (sudut) & $22^{0}$ & $38^{\circ}$ & $22^{0}$ \\
\hline U1-NA (mm) & $4 \mathrm{~mm}$ & $13 \mathrm{~mm}$ & $5 \mathrm{~mm}$ \\
\hline IMPA & $81,5^{0}-97^{0}$ & $90^{\circ}$ & $100^{\circ}$ \\
\hline L1-NB (sudut) & $25^{0}$ & $27^{\circ}$ & $28^{\circ}$ \\
\hline L1-NB (mm) & $4 \mathrm{~mm}$ & $5 \mathrm{~mm}$ & $5 \mathrm{~mm}$ \\
\hline Occl PI-SN & $14^{\circ}$ & $11^{0}$ & $12^{0}$ \\
\hline Occl PI-FHP & $1,5^{0}-14^{0}$ & $5^{0}$ & $6^{0}$ \\
\hline Overbite & $2-4 \mathrm{~mm}$ & $3,64 \mathrm{~mm}$ & $3,5 \mathrm{~mm}$ \\
\hline Overjet & $2-4 \mathrm{~mm}$ & $-3,4 \mathrm{~mm}$ & $3,0 \mathrm{~mm}$ \\
\hline FIS & $105^{0}-115^{0}$ & $122^{\circ}$ & $110^{\circ}$ \\
\hline Posisi bibir atas terhadap garis $S$ & $0 \mathrm{~mm}$ & $4 \mathrm{~mm}$ & $0 \mathrm{~mm}$ \\
\hline Posisi bibir bawah terhadap garis $S$ & $0 \mathrm{~mm}$ & $2 \mathrm{~mm}$ & $0 \mathrm{~mm}$ \\
\hline
\end{tabular}

spring menggunakan kawat 0,012" untuk koreksi mesial dan distal tilting, lingual root torque dan palatal root torque menggunakan kawat 0,012 ", dan chinced back untuk mempertahankan lengkung gigi.

Pada bulan September 2013, perawatan telah dinyatakan selesai dan pada saat ini pasien sedang dalam tahap retensi. Hasil akhir dari perawatan ini adalah oklusi molar klas I, interdigitasi bagian posterior terjaga dengan baik, overbite $3.0 \mathrm{~mm}$, overjet $3.5 \mathrm{~mm}$, dan median line rahang atas dan rahang bawah tidak segaris (pada rahang bawah berada pada pertengahan insisvus sentralis kanan) (gambar 4). Profil pasien terlihat lebih baik dan pasien merasa sangat puas dengan hasil perawatan (gambar 4). Pada hasil analis jaringan lunak sefa- 
lometri diketahui bahwa sebelum perawatan profil wajah atas pasien berada $4 \mathrm{~mm}$ di depan garis $\mathrm{S}$ dan pada rahang bawah $2 \mathrm{~mm}$ di depan garis $\mathrm{S}$. Sesudah perawatan terlihat perubahan dimana profil wajah atas dan bawah pasien tepat berada di garis $S$ (tabel 1). Hasil analisis sefalometri juga menunjukkan seperti yang tertera pada tabel 1 .

\section{PEMBAHASAN}

Beberapa indikasi perawatan ortodontik dengan pencabutan gigi insisivus rahang bawah di antaranya adalah gigi geligi permanen, potensi pertumbuhan minimal, oklusi molar klas I Angle, profil jaringan lunak masih cukup harmonis, pada rahang atas tidak terdapat atau sedikit terdapat gigi berjejal, interdigitasi posterior baik, dan diskrepansi minimal lengkung gigi adalah $5 \mathrm{~mm}{ }^{4,6}$ Pada kasus ini, pasien telah berumur 47 tahun dimana potensi pertumbuhan minimal dan gigi geligi pasien seluruhnya merupakan gigi permanen. Oklusi molar pasien adalah klas I Angle, sedikit gigi berjejal pada rahang atas dan interdigitasi posterior baik. Kekurangan ruang lengkung gigi pada rahang bawah adalah sebesar $4.2 \mathrm{~mm}$. Apabila mengacu pada indikasi kekurangan ruang minimal lengkung gigi adalah $5 \mathrm{~mm}$, kebutuhan ruang pada pasien ini tentu belum termasuk ke dalam kriteria. Akan tetapi, berdasarkan hasil analisis model studi diketahui bahwa gigi 31 mengalami malposisi berupa mesiolabiotorsiversi sehingga dengan pencabutan gigi tersebut akan menghasilkan ruang sebesar $4.2 \mathrm{~mm}$ dan cukup untuk koreksi malposisi gigi individual pada rahang bawah dan retraksi sebesar $2.5 \mathrm{~mm}$. Gigi insisivus rahang bawah dengan derajat malposisi yang paling parah adalah yang dianjurkan untuk dicabut. Hal tersebut dilakukan untuk menghindari gerakan yang berlebihan dan tidak dibutuhkan pada gigi geligi sehingga mencegah relaps pasca perawatan. ${ }^{5}$

Diagnostic setup juga telah dilakukan pada kasus ini untuk melihat prediksi hasil akhir perawatan. Pada diagnostic setup diketahui bahwa dengan pencabutan gigi 31 akan diperoleh hasil perawatan berupa oklusi molar klas I, interdigitasi bagian posterior terjaga dengan baik, overbite
$3.0 \mathrm{~mm}$, overjet $3.5 \mathrm{~mm}$, dan median line rahang atas dan rahang bawah tidak segaris (pada rahang bawah berada pada pertengahan insisvus sentralis kanan). Pada akhir perawatan, semua prediksi yang diperoleh pada diagnostic setup telah tercapai. Diagnostic setup sangat dibutuhkan dalam pengambilan keputusan pencabutan gigi insisivus bawah. Metode perhitungan untuk menentukan diskrepansi lengkung gigi dinilai kurang akurat untuk menunjukkan prediksi hasil perawatan. Diagnostic setup memiliki kemampuan untuk menunjukkan prediksi hasil perawatan lebih akurat. $^{2}$

Pada kasus dengan overjet dan overbite positif yang besar, pencabutan gigi insisivus rahang bawah merupakan kontraindikasi karena akan menambah besarnya overjet dan overbite pada saat penutupan ruang di bagian anterior. ${ }^{5,7}$ Pada kasus ini pasien memiliki overjet yang besar yaitu $5.0 \mathrm{~mm}$ dan overbite sebesar $3.5 \mathrm{~mm}$. Akan tetapi pada kasus ini, pencabutan 1 gigi insisivus rahang bawah tidak menyebabkan penambahan besar overjet dan overbite. Hal tersebut disebabkan oleh mekanika alat cekat teknik Begg. Pada teknik Begg, digunakan anchorage bend sebesar $45^{\circ}$ di interdental gigi P2 dan M1 rahang atas dan rahang bawah. Anchorage bend berfungsi untuk mencegah overbite bertambah besar akibat proses retraksi anterior. $^{8}$

\section{KESIMPULAN}

Pencabutan satu gigi insisivus sentralis rahang bawah pada kasus maloklusi Angle klas I dengan spacing anterior rahang atas dan dilakukan perawatan dengan alat cekat teknik Begg memberikan hasil perawatan yang cukup memuaskan.

\section{DAFTAR PUSTAKA}

1. Iyyer, B.S., Orthodontics The Art and Science, Arya (MEDI) Publishing House, New Delhi, 2004, 239-46

2. Owen, A.H., Single Lower Incisor Extractions, J Clin Orthod, 1993; 27: 153-60 
3. Prakash, A., Tandur, A.P., Dungarwal, N., and Bhargava, R., Mandibular Incisor Extraction Case Report, Virtual Journal of Orthodontics, 2011, 1-6

4. Kokich, V.G., and Shapiro, P.A., Lower Incisor Extraction in Orthodontic Treatment, The Angle Orthodontist, 1984; 54(2): 139-53

5. Canut, J., Mandibular Incisor Extraction: Indications and Long-term Evaluation, European Journal of Orthodontic, 1996; 485-9
6. Valinoti, J.R., Mandibular Incisor Extraction Therapy, Am J Orthod Dentofac Orthop, 1994; 105: $107-16$

7. Zhylich, D., and Suri, S., 2011, Mandibular Incisor Exraction: a Systematic Review of an Uncommon Extraction Choice in Orthodontic Treatment, J British Orthodontic Society, 2011; 1-10

8. Begg, P.R., and Kesling, P.C., Begg Orthodontic Theory and Technique, W.B. Saunder Company, Philadelphia, 1977, 112-3 